\title{
Vacunas contra la COVID-19
}

\author{
COVID-19 vaccines \\ Zurisadai Raquel García Osorno, ${ }^{*}$ Luis Ángel Perón Medina, ${ }^{*}$ Ikky Omar Ramírez Velázquez, ${ }^{*}$ \\ José Antonio Morales Fernández, ${ }^{\ddagger}$ Edson Erivan Mosqueda Martínez, ${ }^{\ddagger}$ Hiram Joaquín Vilchis, ${ }^{\ddagger}$ \\ Alejandra Xóchitl Cruz Salgado, ${ }^{*}$ José Enrique Chávez Aguilar, ${ }^{\ddagger}$ Deyanira Gutiérrez Bautista, ${ }^{\ddagger}$ \\ Leonardo Martín Vásquez Martínez, ${ }^{\ddagger}$ Yazmín Valadez González, ${ }^{\ddagger}$ Luis Alberto Cortázar Maldonado, ${ }^{*}$ \\ Xcarelt Vite Velázquez, ${ }^{*}$ Antonio Humberto Ángel Ambrocio, ${ }^{\ddagger}$ Miguel Leonardo García León, ${ }^{\ddagger}$ \\ Patricia Bautista Carbajal, ${ }^{\ddagger}$ Jorge Baruch Díaz Ramírez, ${ }^{*}$ Rosa María Wong Chew \\ Citar como: García OZR, Perón MLÁ, Ramírez VIO, Morales FJA, Mosqueda MEE, Joaquín VH et al. Vacunas contra \\ la COVID-19. Acta Med Grupo Angeles. 2021; 19 (3): 429-444. https://dx.doi.org/10.35366/101742
}

\section{Resumen}

La aparición del virus SARS-CoV-2 ha generado un alto grado de mortalidad y morbilidad severa en todo el globo, ocasionando la pandemia por COVID-19. Esta situación determinó el surgimiento y desarrollo de distintas vacunas a fin de prevenir la enfermedad grave por COVID-19, así como disminuir el número de decesos generados alrededor del mundo. La elaboración de los preparados actuales contra el padecimiento se basan en cuatro plataformas: material genético del virión, vectores víricos previamente conocidos, virión del SARS-CoV-2 de forma inactivada o que incluyen proteínas antigénicas del virión, todas ellas capaces de generar anticuerpos neutralizantes contra la infección. Estas vacunas han pasado por diferentes fases de investigación, las cuales han determinado la efectividad, seguridad e inmunogenicidad de cada una, así como el empleo y aprobación por la Organización Mundial de la Salud (OMS) y las diferentes agencias regulatorias de salud de cada país. Entre las sustancias actualmente aceptadas por la OMS para su uso de emergencia en el control de la pandemia se encuentran aquellas fabricadas por las compañías de PfizerBioNTech, Oxford-AstraZeneca, Johnson \& Johnson, Moderna, Sinopharm y Sinovac.

Palabras clave: SARS-CoV-2, COVID-19, vacunas.

\section{Abstract}

The appearance of the SARS-CoV-2 virus has generated a high degree of mortality and severe morbidity around the world, leading to the COVID-19 pandemic. This situation led to the emergence and development of different vaccines to prevent severe disease due to such malaise, as well as to reduce the number of deaths worldwide. The development of current COVID-19 vaccines is based on four platforms: genetic material of the virion, previously known viral vectors, inactivated SARS$\mathrm{CoV}-2$ virion, or including antigenic proteins of the virion, all of them capable of generating neutralising antibodies against the infection. These vaccines have gone through different phases of research, which have determined the effectiveness, safety, and immunogenicity of each one, as well as their use and approval by the World Health Organisation (WHO) and the different health regulatory agencies in each country. Among the vaccines currently accepted by the WHO for emergency use to control the pandemic are those manufactured by the companies Pfizer-BioNTech, Oxford-AstraZeneca, Johnson \& Johnson, Moderna, Sinopharm and Sinovac.

Keywords: SARS-CoV-2, COVID-19, vaccines

\footnotetext{
* Clínica de Atención Preventiva del Viajero.

₹ Laboratorio de Investigación en Enfermedades Infecciosas.
}

División de Investigación, Facultad de Medicina, UNAM.

Correspondencia:

Rosa María Wong Chew

Correo electrónico: rmwong@unam.mx

Aceptado: 23-06-2021.

www.medigraphic.com/actamedica

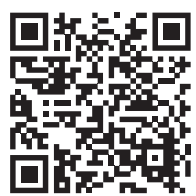

\section{INTRODUCCIÓN}

En diciembre de 2019, se detectó la aparición de una neumonía atípica en Wuhan, China, ocasionada por un nuevo coronavirus, conocido como síndrome respiratorio agudo severo por coronavirus 2 (SARS-CoV-2), que origina la enfermedad por coronavirus 2019 (COVID-19). ${ }^{1}$ El surgimiento de la pandemia por este padecimiento, en marzo de 2020, determinó el despliegue de diferentes vacunas que buscan la prevención de la enfermedad y disminución 
del número de decesos generados alrededor del mundo. Hasta el tres de junio de 2021, en todo el planeta, hay 102 compuestos candidatos contra esta enfermedad, en fase de estudio clínico y 185 candidatos en desarrollo preclínico. ${ }^{2}$

El descubrimiento de una sustancia que combata la COVID-19 es un procedimiento complejo, sometido a cuatro fases de ensayos clínicos, y cuya autorización por las agencias nacionales e internacionales de salud tiene la finalidad de garantizar un proceso de vacunación seguro y efectivo para la población. Sin embargo, el proceso del desarrollo de las distintas preparaciones para hacer frente a la COVID-19 se ha acelerado a un ritmo sin precedentes persiguiendo el control de la pandemia y así disminuir la mortalidad en las distintas regiones del mundo. La OMS ha aceptado el uso de seis marcas para el uso de emergencia contra la pandemia, entre las que se incluyen aquellas fabricadas por las compañías de Pfizer-BioNTech (BNT162b1), Oxford-AstraZeneca (ChadOx1), Johnson \& Johnson (Ad26. COV2.S), Moderna (mRNA-1273/83), Sinopharm (BBIBPCorV) y Sinovac (CoronaVac). ${ }^{1}$

En esta revisión se plantea un panorama general de las plataformas vacunales aceptadas por las distintas agencias regulatorias alrededor del mundo hacia la prevención de la COVID-19, así como sus principales características de eficacia, seguridad, e inmunogenicidad para el control de la pandemia.

\section{FASES DE ESTUDIO DE LAS VACUNAS}

La generación de vacunas contra distintas enfermedades infecciosas es sometida a varios ciclos de estudio de investigación a fin de determinar las características de su eficacia, seguridad e inmunogenicidad para poder ser aplicadas a la población. Las sustancias se someten a un total de seis etapas de análisis buscando su aprobación; dos fases de investigación, que incluyen la búsqueda de compuestos candidatos y la aplicación en modelos usando animales o líneas celulares, y cuatro ciclos de investigación en el ser humano. Entre estas etapas de búsqueda se incluyen (Figura 1):

Fase exploratoria: su objetivo es la identificación de los antígenos virales o vacunas candidatas para su elaboración; dicha etapa suele durar de dos a cuatro años de estudio. ${ }^{2-4}$

Fase preclínica: se realizan los análisis de las mezclas candidatas en modelos con animales y cultivos celulares a

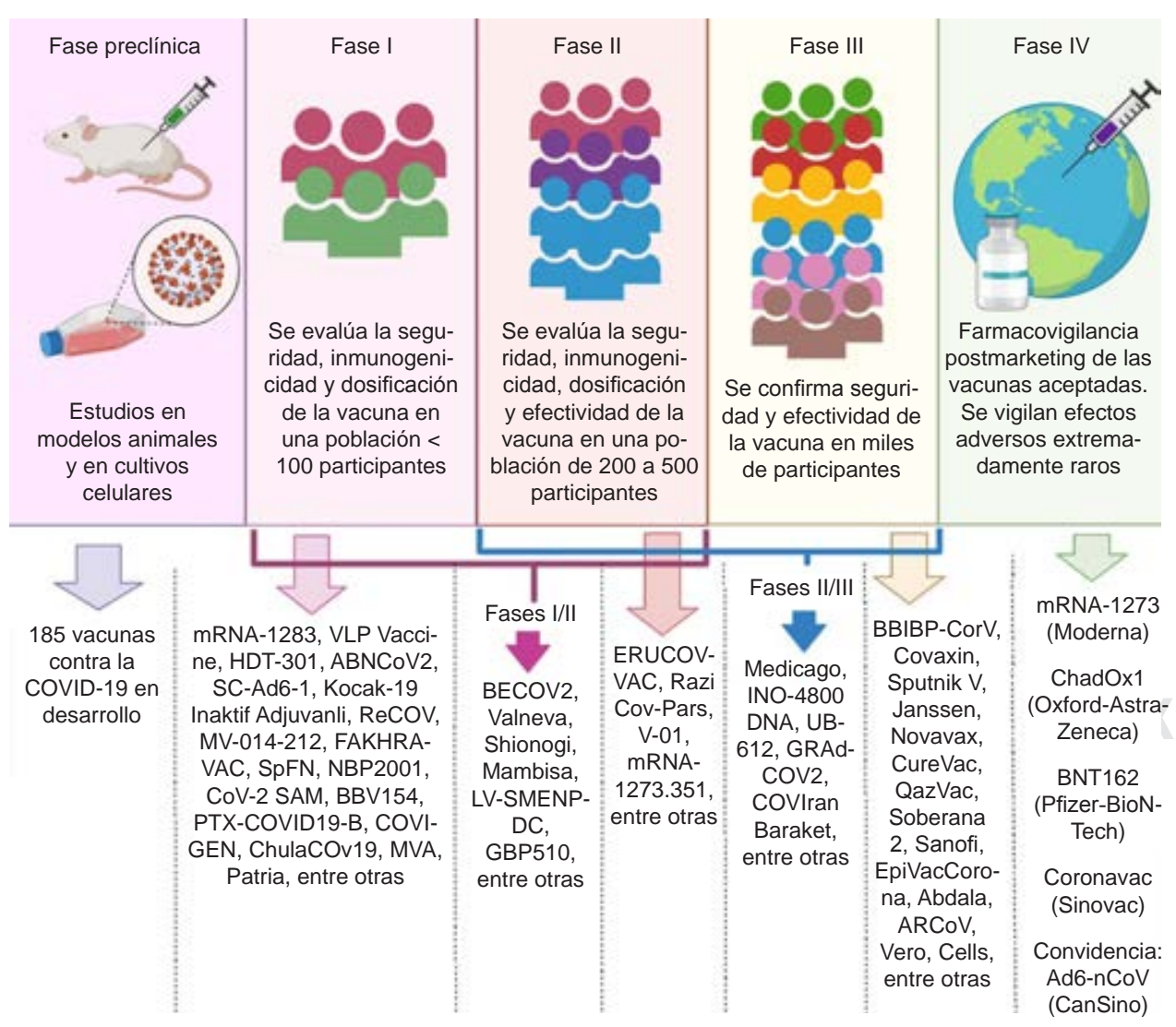

Figura 1:

Fases de estudio en el desarrollo de vacunas contra la COVID-19 según su estudio hasta el 03 de junio de 2021 . $^{2}$ 
fin de determinar su seguridad e inmunogenicidad para ser aplicadas en los seres humanos; esta temporada acostumbra durar de uno a dos años de trabajo. Actualmente, 184 mixturas contra la COVID-19 se encuentran en tal fase. ${ }^{2-4}$

Fase I: su meta es evaluar inicialmente la seguridad, dosificación, forma de aplicación, inmunogenicidad y posibles efectos adversos de las vacunas, previamente utilizadas en modelos animales y líneas celulares, en un número reducido de personas ( $<100$ participantes); esta etapa suele durar un año para su estudio. En la actualidad, 35 sustancias contra ese trastorno se hallan en este ciclo. ${ }^{2-4}$

Fase II: su propósito es explorar de manera más detallada la seguridad, inmunogenicidad, dosificación propuesta e iniciar la investigación de la eficacia de tales biológicos en grupos más extensos de personas (200 a 500 participantes); tal etapa regularmente requiere de dos a tres años para su culminación. Hoy en día, 36 vacunas contra la COVID-19 se encuentran en esta temporada. ${ }^{2-4}$

Fase III: son pocas las sustancias que llegan a esta altura, cuyo objetivo es la confirmación y evaluación de la seguridad y eficacia vacunal comparadas contra un placebo, en miles de personas en uno o varios países, así como la comprobación de efectos adversos poco frecuentes en un grupo grande de la población; esta etapa es previa a la aprobación y suele requerir de dos a cuatro años para su terminación. Actualmente, 25 composiciones se ubican en dicha fase, y 15 de éstas siendo aplicadas en la población general, entre las que si incluyen: BBIBP-CorV, Covaxin, Sputnik V, Janssen, Novavax, QazVac, CureVac, Sanofi Pasteur/GSK, Soberana 2, EpiVacCorona, Abdala, Zydus Cadila, ARCoV, Vero Cells y VLA2001.2-4

Fase IV: es la parte final posterior a la aprobación por las agencias regulatorias nacionales, que implica un seguimiento adicional a la población (farmacovigilancia) durante un periodo de tiempo más largo postmarketing. En el presente, cinco vacunas se encuentran en esa etapa, entre las que se cuentan: Pfizer-BioNTech, Moderna, Oxford-AstraZeneca, Sinovac, y CanSino. ${ }^{2-4}$

Sin embargo, la pandemia por COVID-19 ha requerido una aceleración en el proceso del desarrollo de vacunas, por lo que en tales situaciones de emergencia las fases de estudio se acortan juntando la I y II o la II y III camino a la realización de los estudios clínicos sobre plataformas preexistentes para su elaboración. Este hecho ha provocado que las sustancias contra esta enfermedad sean las primeras con menor tiempo en su fabricación y aprobación a lo largo de la historia (Figura 1 y Tabla 1).

\section{PLATAFORMAS PARA EL DESARROLLO DE VACUNAS}

En la elaboración de combinados contra la COVID-19 se han utilizado 4 plataformas (Figura 2 y Tabla 1):
Vacunas de ácidos nucleicos: se trata de una tecnología relativamente nueva, que utiliza material genético (ADN o ARN) de un virus o bacteria causante de la enfermedad, buscando estimular una reacción inmunitaria contra él. En el caso del SARS-CoV-2 se utiliza el ARN mensajero (ARNm) para la fabricación de una proteína específica del patógeno (proteína S), que el sistema inmunitario reconocerá como extraña (un antígeno). Una vez insertado en las células del hospedero, este material genético se traduce hacia la producción de la proteína $S$, que desencadena una respuesta inmunitaria y genera la producción de anticuerpos. Entre sus características principales destacan que no contienen componentes vivos, por lo que no hay riesgo de que la vacuna desencadene una enfermedad; son relativamente fáciles de fabricar, requieren un almacenamiento en frío y pueden requerir inyecciones de refuerzo. Entre las vacunas contra la COVID-19 con esta plataforma se encuentran las marcas de Pfizer-BioNTech, Moderna, CureVac, ARCoV, Zydus Cadila, Osaka University/Anges, Inovio Pharmaceutical, entre otras. ${ }^{2,5}$

Vacunas basadas en vectores virales: este tipo de biológicos no contienen antígenos, sino que utilizan las propias células del hospedero, intentando producirlos. Existen dos tipos principales de sustancias: aquellas que contienen vectores no replicantes que sólo producen el antígeno de la vacuna, y otras con vectores replicantes que generan nuevas partículas virales en las células hospederas y a la vez infectan nuevas células que producirán el antígeno de la vacuna. La mayoría de las sustancias de vectores virales contra la COVID-19 utilizan los primeros, y con tal fin, utilizan un virus modificado (vector-adenovirus) para introducir en las células humanas el código genético del antígeno, que en el caso del SARS-CoV-2 es la proteína espiga o proteína S. Al infectar las células y originar la producción del antígeno, se desencadena una reacción inmunitaria, que imita una infección natural. Esto tiene la ventaja de desencadenar una fuerte respuesta inmunitaria celular (células T) y humoral (células B). Entre las vacunas contra el trastorno comentado, con esta plataforma se encuentran las de Oxford-AstraZeneca, Janssen de Johnson \& Johnson, Sputnik V, CanSino, Patria de Laboratorio AVI-MEX, GRAd-COV2 de ReiThera, entre otras. 2,5

Vacunas con virus vivos atenuados/inactivados: este tipo de plataforma utiliza una forma debilitada (atenuada) o inactivada del patógeno que causa una enfermedad para desencadenar una inmunidad protectora contra él. Existen dos tipos vacunales: aquellas atenuadas que utilizan una forma debilitada del virus, que todavía puede replicarse, pero no causa la enfermedad; y por otro lado, las inactivadas que contienen virus cuyo material genético ha sido deshabilitado por medios térmicos, 
Tabla 1: Información general sobre las distintas vacunas contra la COVID-19 hasta el 03 de junio de 2021.

\begin{tabular}{|c|c|c|c|c|c|c|c|c|}
\hline $\begin{array}{l}\text { Plataforma } \\
\text { vacunal }\end{array}$ & $\begin{array}{l}\text { Nombre de la } \\
\text { vacuna }\end{array}$ & Compañía & $\begin{array}{l}\text { Fase de } \\
\text { desarrollo }\end{array}$ & $\begin{array}{c}\text { Eficacia } \\
\text { general (\%) }\end{array}$ & Dosificación & $\begin{array}{l}\text { Efectos } \\
\text { adversos (EA) }\end{array}$ & $\begin{array}{c}\text { Respuesta ante } \\
\text { variantes genéticas del } \\
\text { SARS-CoV-2 }\end{array}$ & $\begin{array}{l}\text { Aprobación para su } \\
\text { uso de emergencia }\end{array}$ \\
\hline \multirow[t]{7}{*}{$\begin{array}{l}\text { Vacunas } \\
\text { de ácidos } \\
\text { nucleicos }\end{array}$} & $\begin{array}{l}\text { BNT162b1 } \\
\text { (ARNm) }\end{array}$ & Pfizer/BioNTech & IV & 94.6 & $\begin{array}{l}2 \text { dosis de } \\
0.5 \mathrm{~mL} \text { vía IM } \\
\text { con } 21 \text { días } \\
\text { interdosis }\end{array}$ & $\begin{array}{l}\text { Dolor, hinchazón } \\
\text { y enrojecimiento } \\
\text { en el sitio de } \\
\text { la inyección, } \\
\text { fatiga, mialgias, } \\
\text { escalofríos, } \\
\text { artralgias, diarrea } \\
\text { y fiebre }\end{array}$ & $\begin{array}{c}\text { Demostró protección } \\
\text { contra las variantes } \\
\text { B.1.1.7 (89.5\%) y contra } \\
\text { la variante B.1.351 } \\
\text { (75\%) }\end{array}$ & $\begin{array}{c}\text { Primera vacuna } \\
\text { aprobada por la OMS } \\
\text { el } 31 \text { de diciembre } \\
\text { del } 2020\end{array}$ \\
\hline & $\begin{array}{l}\text { mRNA-1273/83 } \\
\text { (ARNm) }\end{array}$ & Moderna/NIAID & IV & 94.1 & $\begin{array}{l}2 \text { dosis de } \\
0.5 \mathrm{~mL} \text { vía IM } \\
\text { con } 28 \text { días } \\
\text { interdosis }\end{array}$ & $\begin{array}{c}\text { Dolor en el sitio de } \\
\text { la inyección, fatiga y } \\
\text { mialgias } \\
\text { EA extremadamente } \\
\text { raros: COVID Arm }\end{array}$ & $\begin{array}{l}\text { Demostró protección } \\
\text { reducida, pero } \\
\text { significativa, contra la } \\
\text { variante } B .1 .351\end{array}$ & $\begin{array}{l}\text { Cuarta vacuna } \\
\text { aprobada por la } \\
\text { OMS el } 30 \text { de abril } \\
\text { del } 2021\end{array}$ \\
\hline & $\begin{array}{l}\text { ZyCoV-D (plás- } \\
\text { mido de ADN) }\end{array}$ & Zydus Cadila & III & NR & $\begin{array}{l}3 \text { dosis vía ID } \\
\text { con } 28 \text { días } \\
\text { interdosis }\end{array}$ & $\mathrm{NR}$ & NR & - \\
\hline & $\begin{array}{l}\text { CVnCoV } \\
\text { (ARNm) }\end{array}$ & CureVac & III & NR & $\begin{array}{l}2 \text { dosis vía IM } \\
\text { con } 28 \text { días } \\
\text { interdosis }\end{array}$ & NR & $\begin{array}{c}\text { Demostró protección } \\
\text { contra la variante B } \\
1.351 \text { en los estudios } \\
\text { preclínicos }\end{array}$ & - \\
\hline & ARCoV (ARNm) & $\begin{array}{l}\text { Academy of } \\
\text { Military Medical } \\
\text { Sciences/ } \\
\text { Suzhou Abogen } \\
\text { Biosciences/ } \\
\text { Walvax } \\
\text { Biotechnology }\end{array}$ & III & NR & $\begin{array}{l}2 \text { dosis vía IN } \\
\text { con } 28 \text { días } \\
\text { interdosis }\end{array}$ & NR & NR & - \\
\hline & $\begin{array}{l}\text { INO-4800 } \\
\text { (ADN) }\end{array}$ & $\begin{array}{c}\text { Inovio } \\
\text { Pharmaceutical }\end{array}$ & $\|/\| I$ & NR & $\begin{array}{l}2 \text { dosis vía ID } \\
\text { con } 28 \text { días } \\
\text { interdosis }\end{array}$ & NR & NR & - \\
\hline & $\begin{array}{l}\text { mRNA- } \\
1273.351\end{array}$ & Moderna/NIAID & ॥ & NR & $\begin{array}{l}3 \text { dosis vía IM } \\
\text { con } 28 \text { días } \\
\text { interdosis }\end{array}$ & NR & $\begin{array}{c}\text { Falta mayor estudio, } \\
\text { sin embargo, como su } \\
\text { nombre lo indica, está } \\
\text { dirigida contra la variante } \\
\text { B } 1.351\end{array}$ & - \\
\hline
\end{tabular}

Vacunas en fases I/II: COVID-eVax (ADN) de Takis/Rottapharm Biotech (Italia); DS-5670a (ARN) de Daiichi Sankyo Co.(Japón); EXG-5003 (ARN) de Elixirgen Therapeutics (Estados Unidos), entre otras. Vacunas en fase I: Covigenix VAX-001 (ADN) de Entos Pharmaceuticals Inc (Canadá); COVIGEN (ADN) de BioNet-Asia (Australia); PTX-COVID19-B (ARN) de Providence Therapeutics; CoV-2 SAM (ARN) de GlaxoSmithKline (Reino Unido), ChulaCOv19 de Chula Vaccine Research Center (Tailandia), HDT-301 de Sinai Cimatec (Brasil), mRNA-1273 de Modernatx Inc (Estados Unidos), entre otras.

\begin{tabular}{|c|c|c|c|c|c|c|c|c|}
\hline \multirow[t]{3}{*}{$\begin{array}{l}\text { Vacunas } \\
\text { con vectores } \\
\text { virales no } \\
\text { replicativos }\end{array}$} & $\begin{array}{l}\text { ChAdOx1 } \\
\text { nCoV-19 }\end{array}$ & $\begin{array}{l}\text { AstraZeneca/ } \\
\text { Oxford }\end{array}$ & IV & $\begin{array}{c}59.9 \text { hasta } \\
81.3\end{array}$ & $\begin{array}{l}2 \text { dosis de } 0.5 \\
\text { mL vía IM con } 4 \\
\text { a } 12 \text { semanas } \\
\text { interdosis }\end{array}$ & $\begin{array}{c}\text { Enrojecimiento, } \\
\text { aumento de la } \\
\text { temperatura e } \\
\text { hinchazón en el sitio } \\
\text { de la inyección, fatiga, } \\
\text { cefalea, mialgias, } \\
\text { escalofríos, artralgias } \\
\text { y fiebre } \\
\text { EA extremadamente } \\
\text { raros: trombosis } \\
\text { trombocitopénica }\end{array}$ & $\begin{array}{c}\text { Demostró una eficacia } \\
\text { del } 74.6 \% \text { contra } \\
\text { la variante B.1.1.7. } \\
\text { de acuerdo con su } \\
\text { estudio de fase } 3 \text { en } \\
\text { Reino Unido. No se } \\
\text { demostró protección } \\
\text { contra la variante } \\
\text { B.1.351 }(10.4 \%)\end{array}$ & $\begin{array}{c}\text { Segunda vacuna } \\
\text { aprobada por la OMS } \\
\text { el } 15 \text { de febrero del } \\
2021\end{array}$ \\
\hline & $\begin{array}{l}\text { Convidecia } \\
\text { (Ad5-nCoV) }\end{array}$ & $\begin{array}{l}\text { CanSino Biological } \\
\text { Inc. }\end{array}$ & IV & 65.7 & 1 dosis vía IM & $\begin{array}{l}\text { Dolor en el sitio de } \\
\text { aplicación, fatiga, } \\
\text { cefalea, mialgias, } \\
\text { fiebre y artralgia }\end{array}$ & & - \\
\hline & $\begin{array}{l}\text { Sputnik V } \\
\text { (rAd26-S y } \\
\text { rAd5-S) }\end{array}$ & Gamaleya & III & 91.6 & $\begin{array}{l}2 \text { dosis de } \\
0.5 \mathrm{~mL} \text { vía IM } \\
\text { con } 21 \text { días } \\
\text { interdosis }\end{array}$ & $\begin{array}{l}\text { Enfermedad similar a } \\
\text { la gripe, reacciones } \\
\text { locales en el sitio de } \\
\text { la inyección, cefalea y } \\
\text { astenia }\end{array}$ & $\begin{array}{l}\text { De acuerdo con } \\
\text { reportes preliminares } \\
\text { de un ensayo fase } 3 \\
\text { realizado en Argentina, } \\
\text { se demostró eficacia } \\
\text { contra la cepa B.1.1.7 } \\
\text { pero no contra la } \\
\text { B.1.351 }\end{array}$ & - \\
\hline
\end{tabular}




\section{Continuación de la Tabla 1: Información general sobre las distintas vacunas contra la COVID-19 hasta el 03 de junio de 2021.}

\begin{tabular}{|c|c|c|c|c|c|c|c|c|}
\hline $\begin{array}{l}\text { Plataforma } \\
\text { vacunal }\end{array}$ & $\begin{array}{c}\text { Nombre de la } \\
\text { vacuna }\end{array}$ & Compañía & $\begin{array}{c}\text { Fase de } \\
\text { desarrollo }\end{array}$ & $\begin{array}{c}\text { Eficacia } \\
\text { general (\%) }\end{array}$ & Dosificación & $\begin{array}{c}\text { Efectos } \\
\text { adversos (EA) }\end{array}$ & $\begin{array}{c}\text { Respuesta ante } \\
\text { variantes genéticas del } \\
\text { SARS-CoV-2 }\end{array}$ & $\begin{array}{l}\text { Aprobación para su } \\
\text { uso de emergencia }\end{array}$ \\
\hline & $\begin{array}{c}\text { Janssen (Ad26. } \\
\text { COV2.S) }\end{array}$ & $\begin{array}{c}\text { Johnson \& } \\
\text { Johnson }\end{array}$ & III & $57-72$ & 1 dosis vía IM & $\begin{array}{c}\text { Dolor en el sitio de } \\
\text { la inyección, cefalea, } \\
\text { fatiga, mialgias y } \\
\text { náuseas } \\
\text { EA extremadamente } \\
\text { raros: trombosis } \\
\text { trombocitopénica }\end{array}$ & $\begin{array}{l}\text { Demostró protección } \\
\text { contra las variantes } \\
\text { P.2 y B.1.351 de } \\
\text { acuerdo con su } \\
\text { estudio fase III }\end{array}$ & $\begin{array}{c}\text { Tercera vacuna } \\
\text { aprobada por la OMS } \\
\text { el } 12 \text { de marzo del } \\
2021\end{array}$ \\
\hline & GRAd-COV2 & ReiThera & $\|/ /\| \|$ & NR & 1 dosis vía IM & NR & NR & - \\
\hline
\end{tabular}

Vacunas en fases IIII: LV-SMENP-DC de Shenzhen Geno-Immune Medical Institute (China); NDV-HXP-S de Mahidol University (Tailandia); VBI-2902a de VBI Vaccines Inc (Estados Unidos); COVIVAC del Institute of Vaccines and Medical Biologicals (Vietnam), entre otras.

Vacunas en fase I: Modified Vaccinia Ankara (MVA) de City of Hope (Estados Unidos), BBV154 de Bharat Biotech (India), SC-Ad6-1 de Tetherex Pharmaceuticals Corporation (Estados Unidos), ABNCoV2 de Radboud University (Países Bajos), entre otras.

\begin{tabular}{|c|c|c|c|c|c|c|c|c|}
\hline \multirow[t]{7}{*}{$\begin{array}{l}\text { Vacunas con } \\
\text { virus vivos } \\
\text { atenuados o } \\
\text { inactivados }\end{array}$} & CoronaVac & Sinovac & IV & $\begin{array}{l}50.6 \text { hasta } \\
91.0\end{array}$ & $\begin{array}{l}2 \text { dosis vía IM } \\
\text { con } 14 \text { días } \\
\text { interdosis }\end{array}$ & $\begin{array}{c}\text { Reacciones } \\
\text { locales (39.0\%): } \\
\text { dolor en el sitio } \\
\text { de aplicación, } \\
\text { exantema, } \\
\text { eritema, } \\
\text { induración, } \\
\text { mialgias. } \\
\text { Reacciones } \\
\text { sistémicas } \\
\text { (45.7\%): cefalea, } \\
\text { fatiga, mialgias, } \\
\text { fiebre, diarrea, } \\
\text { escalofríos }\end{array}$ & $\begin{array}{l}\text { Demostró protección } \\
\text { ante la variante P.1 de } \\
\text { acuerdo con un estudio } \\
\text { realizado en Brasil }\end{array}$ & $\begin{array}{c}\text { Sexta vacuna } \\
\text { aprobada por la OMS } \\
\text { el } 01 \text { de junio del } \\
2021\end{array}$ \\
\hline & BBIBP-CorV & Sinopharm Group & III & 86.0 & $\begin{array}{c}2 \text { dosis vía IM } \\
\text { de } 0.5 \mathrm{~mL} \text { con } \\
21 \text { a } 28 \text { días } \\
\text { interdosis }\end{array}$ & $\begin{array}{c}\text { Dolor, eritema, } \\
\text { prurito, edema, } \\
\text { hinchazón y rash } \\
\text { en el sitio de la } \\
\text { inyección, fatiga, } \\
\text { fiebre transitoria, } \\
\text { cefalea, diarrea, } \\
\text { tos, disnea, } \\
\text { náuseas, vómito, } \\
\text { mialgias, artralgias, } \\
\text { somnolencia, } \\
\text { mareos y anorexia }\end{array}$ & $\begin{array}{c}\text { Demostró protección } \\
\text { ante la variante } 501 Y . V 2\end{array}$ & $\begin{array}{c}\text { Quinta vacuna } \\
\text { aprobada por la OMS } \\
\text { el } 07 \text { de mayo del } \\
2021\end{array}$ \\
\hline & $\begin{array}{l}\text { COVAXIN } \\
\text { (BBV152) }\end{array}$ & Bharat Biotech & III & 81.0 & $\begin{array}{l}2 \text { dosis vía IM } \\
\text { con } 28 \text { días } \\
\text { interdosis }\end{array}$ & $\begin{array}{l}\text { Dolor, hinchazón, } \\
\text { eritema y prurito en el } \\
\text { sitio de la inyección, } \\
\text { cefalea, fiebre, } \\
\text { malestar general, } \\
\text { mialgias, náusea, } \\
\text { vómitos y erupciones }\end{array}$ & $\begin{array}{l}\text { De acuerdo con repor- } \\
\text { tes preliminares puede } \\
\text { neutralizar las cepas } \\
\text { variantes del Reino } \\
\text { Unido }\end{array}$ & - \\
\hline & QazVac & $\begin{array}{l}\text { Research Institute } \\
\text { for Biological } \\
\text { Safety Problems }\end{array}$ & III & NR & $\begin{array}{l}2 \text { dosis vía IM } \\
\text { con } 21 \text { días } \\
\text { interdosis }\end{array}$ & NR & NR & - \\
\hline & Vero Cells & $\begin{array}{c}\text { Shenzhen } \\
\text { Kangtai Biological } \\
\text { Products }\end{array}$ & III & NR & $\begin{array}{l}2 \text { dosis vía IM } \\
\text { con } 21 \text { días } \\
\text { interdosis }\end{array}$ & NR & NR & - \\
\hline & $\begin{array}{l}\text { COVIran } \\
\text { Barekat }\end{array}$ & $\begin{array}{l}\text { Shifa Pharmed } \\
\text { Industrial Co. }\end{array}$ & $\| / / I I$ & NR & $\begin{array}{l}2 \text { dosis vía IM } \\
\text { con } 14 \text { días } \\
\text { interdosis }\end{array}$ & NR & NR & - \\
\hline & ERUCOV-VAC & Erciyes University & ॥ & NR & $\begin{array}{l}2 \text { dosis vía IM } \\
\text { con } 21 \text { días } \\
\text { interdosis }\end{array}$ & NR & NR & - \\
\hline
\end{tabular}

Vacunas en fases I/II: KD-414 de KM Biologics Co. LTD (Japón)

Vacunas en fase I: Patria (IM e IN) del Laboratorio AVI-MEX (vector- Virus de la enfermedad de Newcastle)-México, MV-014-212 de Meissa Vaccines (Estados Unidos); Koçak-19 Inaktif Adjuvanlı de Koçak Farma (Turquía), FAKHRAVAC (MIVAC) de la Organization of Defensive Innovation and Research (Iran), entre otras. 
Continuación de la Tabla 1: Información general sobre las distintas vacunas contra la COVID-19 hasta el 03 de junio de 2021.

\begin{tabular}{|c|c|c|c|c|c|c|c|c|}
\hline $\begin{array}{l}\text { Plataforma } \\
\text { vacunal }\end{array}$ & $\begin{array}{c}\text { Nombre de la } \\
\text { vacuna }\end{array}$ & Compañía & $\begin{array}{l}\text { Fase de } \\
\text { desarrollo }\end{array}$ & $\begin{array}{c}\text { Eficacia } \\
\text { general (\%) }\end{array}$ & Dosificación & $\begin{array}{c}\text { Efectos } \\
\text { adversos (EA) }\end{array}$ & $\begin{array}{c}\text { Respuesta ante } \\
\text { variantes genéticas del } \\
\text { SARS-CoV-2 }\end{array}$ & $\begin{array}{l}\text { Aprobación para su } \\
\text { uso de emergencia }\end{array}$ \\
\hline \multirow[t]{7}{*}{$\begin{array}{l}\text { Vacunas con } \\
\text { subunidades } \\
\text { proteicas } \\
\text { virales }\end{array}$} & $\begin{array}{l}\text { Covovax (NVX- } \\
\text { CoV2373) }\end{array}$ & Novavax & III & 89.3 & $\begin{array}{l}2 \text { dosis vía IM } \\
\text { con } 21 \text { días } \\
\text { interdosis }\end{array}$ & $\begin{array}{c}\text { Dolor en el sitio de } \\
\text { la inyección, cefalea, } \\
\text { mialgias y fatiga }\end{array}$ & $\begin{array}{c}\text { Demostró protección } \\
\text { contra la variante B.1.1.7 } \\
\text { en reportes preliminares } \\
\text { con } 89.3 \% \text {, pero no } \\
\text { contra la variante B } \\
1.351(49.4 \%)\end{array}$ & - \\
\hline & Soberana 2 & $\begin{array}{l}\text { Instituto Finlay de } \\
\text { Vacunas }\end{array}$ & III & NR & $\begin{array}{l}2 \text { dosis vía IM } \\
\text { con } 28 \text { días } \\
\text { interdosis }\end{array}$ & NR & NR & - \\
\hline & EpiVacCorona & Vector Institute & III & NR & $\begin{array}{l}2 \text { dosis vía IM } \\
\text { con } 21 \text { días } \\
\text { interdosis }\end{array}$ & NR & NR & - \\
\hline & VAT00002 & $\begin{array}{c}\text { Sanofi Pasteur } \\
+ \text { GSK }\end{array}$ & III & NR & $\begin{array}{l}2 \text { dosis vía IM } \\
\text { con } 21 \text { días } \\
\text { interdosis }\end{array}$ & NR & NR & - \\
\hline & $\begin{array}{c}\text { Abdala (CIGB } \\
66)\end{array}$ & $\begin{array}{c}\text { Center for Genetic } \\
\text { Engineering and } \\
\text { Biotechnology of } \\
\text { Cuba }\end{array}$ & III & NR & $\begin{array}{l}3 \text { dosis vía } \\
\text { IN con cada } \\
14 \text { o } 28 \text { días } \\
\text { interdosis }\end{array}$ & NR & NR & - \\
\hline & CoVLP & Medicago Inc. & II/III & NR & $\begin{array}{l}2 \text { dosis vía IN } \\
\text { con } 21 \text { días } \\
\text { interdosis }\end{array}$ & NR & NR & - \\
\hline & UB-612 & $\begin{array}{l}\text { Vaxxinity } \\
\text { (COVAXX) }\end{array}$ & II/III & NR & $\begin{array}{l}2 \text { dosis vía IM } \\
\text { con } 28 \text { días } \\
\text { interdosis }\end{array}$ & NR & NR & - \\
\hline
\end{tabular}

Vacunas en fase II: V-01 de Guangdong Providencial Center for Disease Control and Prevention (China), Razi Cov-Pars de The Razi Vaccine and Serum Research Institute (Iran).

Vacunas en fases IIII: BECOV2 de Biological E LTD (India); Mambisa de The Center for Genetic Engineering and Biotechnology of Cuba (Cuba), GBP510 de SK Bioscience (Corea del Sur), Soberana 1 del Instituto Finlay de Vacunas (Cuba), EuCorVac-19 de EuBiologics LTD; CO (Corea del Sur), entre otras.

Vacunas en fase I: ReCOV de Jiangsu Rec-Biotechnology (China), SpFN de Walter Reed Army Institute of Research (Estados Unidos); NBP2001 de SK Bioscience (Corea del Sur); CoVePiT de OSE Inmunotherapeutics (Francia), CoV2-OGEN1 de Vaxform (Estados Unidos), entre otras.

IM = intramuscular; ID = intradérmica; IN: intranasal, NR = no reportado.

químicos o radiactivos, de modo que pueden replicarse en las células hospederas, pero sí desencadenan una respuesta inmunitaria contra el virión. Entre aquellas contra la COVID-19 usando esta plataforma se encuentran CoronaVac de Sinovac, BBIBP-CorV de Sinopharm, Covaxin de Bharat Biotech, Vero Cells, QazVac, COVIran Barekat, entre otras. ${ }^{2,5}$

Vacunas con subunidades proteicas o acelulares: este tipo de mixturas contienen fragmentos purificados del virión, que han sido especialmente seleccionados por su capacidad para estimular las células inmunitarias e incapacidad de generar la enfermedad, por lo que se consideran muy seguras. Existen varios tipos vacunales: de subunidades proteicas, de polisacáridos y de subunidades conjugadas; sin embargo, aquellas contra este padecimiento incluyen sólo el primer tipo, las cuales contienen proteínas específicas aisladas de patógenos virales (proteína S). Entre las propuestas contra la COVID-19 con esta plataforma se encuentran las de Novavax, Sanofi Pasteur/GSK, Soberana 2, EpiVacCorona, Abdala, Medicago, Vaxxinity, entre otras. ${ }^{2,5}$

\section{VACUNAS CON ESTUDIOS FASES III Y IV}

Vacunas de ácidos nucleicos (ARNm)

PFIZER/BIONTECH: BNT162b2

En marzo de 2020, BioNTech y Pfizer acordaron desplegar en conjunto una vacuna contra el SARS-CoV-2. Dicha colaboración surgiría a partir del año 2018, tras un pacto entre ambos laboratorios para desarrollar aquellas basadas en ARNm contra la influenza. El 31 de diciembre de 2020, BNT162b2 se convierte en la primera vacuna COVID-19 en recibir la validación de emergencia por la Organización Mundial de la Salud y el 14 de febrero de 2021 se vuelve la primera sustancia anti-COVID-19 en recibir la aprobación especial de emergencia en Japón. ${ }^{6}$

BNT162b2 es una preparación basada en ARNm que codifica una proteína S mutante P2 (P2 S) del SARS-CoV-2, modificada con nucleósidos mediante la sustitución de la molécula uridina. ${ }^{7}$ La BNT162b2 está formulada con nanopartículas lipídicas (NPLs), cuya función es encapsular 

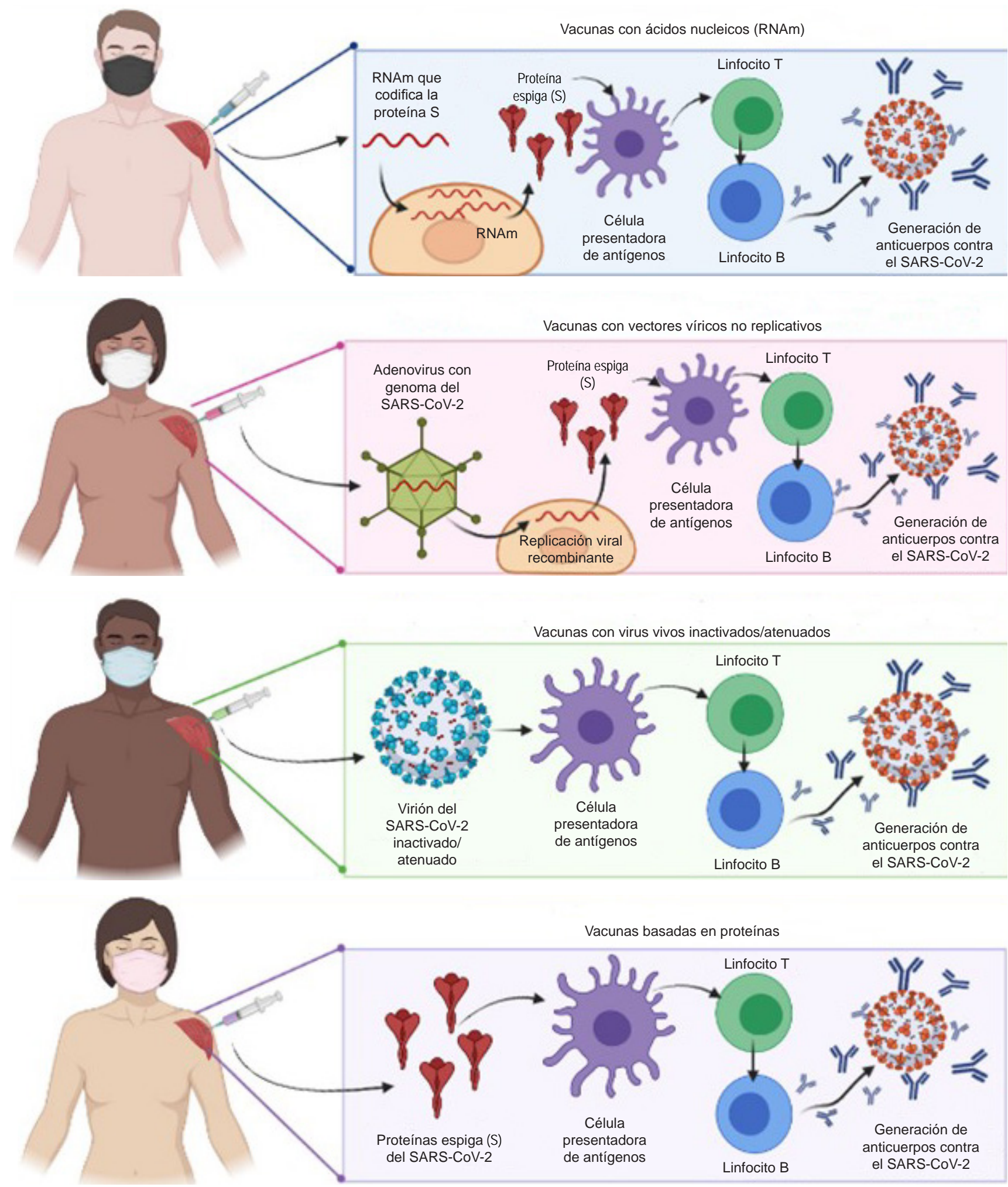

Figura 2: Mecanismos de acción de los cuatro tipos de plataformas vacunales contra la COVID-19 empleadas para las distintas vacunas en investigación. 
el ARN no replicante al mezclarse, protegiéndolo de su degradación y permitiendo la transfección del material genético a las células del hospedero. Una vez dentro, el ARNm se traduce en la proteína S del SARS-CoV-2, para ser procesada y expresada en la superficie de las células e inducir una respuesta inmune mediante la producción de anticuerpos neutralizantes y respuestas inmunitarias celulares. ${ }^{8}$

La vacuna BNT162b2 está disponible en un vial de dosis múltiple (cinco partes de $30 \mu$ g cada una) que contiene un producto congelado entre -80 y $-60^{\circ} \mathrm{C}$, lo cual supone un reto logístico en su distribución. BNT162b2 se administra por vía intramuscular en un régimen de dos inyecciones, con un intervalo de 21 días entre cada una. En caso de descongelarse y diluirse, y no ser utilizada al momento, las ampolletas deberán almacenarse entre dos y $25^{\circ} \mathrm{C}$ y utilizarse dentro de las siguientes seis horas. ${ }^{9} \mathrm{~A}$ partir de los resultados obtenidos en la fase III y su análisis por los Centros para el Control y la Prevención de Enfermedades (CDC), se recomienda aplicar la BNT162b2 en personas mayores de 12 años de edad. ${ }^{10,11}$

BNT162b2 reveló una eficacia entre la dosis uno y la dos de $52.4 \%$, mientras que su eficacia es mayor entre la segunda parte y siete días después de la aplicación de ésta, siendo de 95\% para la prevención de COVID-19 en personas sin evidencia serológica o virológica de infección previa o existente de SARS-CoV- $2 .^{8}$

La efectividad vacunal de BNT162b2, obtenida a partir del estudio realizado por la organización sanitaria de Israel, arrojó los siguientes resultados: ${ }^{12}$

1. Efectividad estimada durante los días 14 a 20 después de la primera dosis: infección documentada con SARSCoV-2 46\%; COVID-19 sintomático 57\%; hospitalización relacionada con este mal $74 \%$; enfermedad grave $62 \%$ y muerte $72 \%$.

2. Efectividad estimada durante los días 21 a 27 (lapso entre la primera y segunda aplicación): infección documentada con SARS-CoV-2 60\%; COVID-19 sintomático 66\%; hospitalización relacionada con este contagio $78 \%$; enfermedad grave $80 \%$ y muerte $84 \%$.

3. Efectividad estimada siete días después de la segunda dosis: infección documentada con SARS-CoV-2 92\%; COVID-19 sintomático 94\%; hospitalización relacionada con el trastorno $87 \%$ y enfermedad grave $92 \%$.

BNT162b2 demostró una efectividad de $89.5 \%$ contra la variante B.1.1.7, posterior 14 días o más a la aplicación de la segunda inyección. La efectividad evidenciada contra la variante B.1.351 fue de 75\%. La efectividad final de ambas variantes contra la enfermedad grave, crítica o mortal fue de $97.4 \% .^{13}$
En el estudio fase II/III de BNT162b2, los principales efectos adversos locales en personas de entre 16 y 55 años y mayores de 55 años, fueron: dolor en el sitio de la inyección (dosis 1: 83 versus $71 \%$ ), (dosis 2: 78 versus $66 \%$ ), hinchazón en el sitio de la inyección (dosis 1: 6 versus $7 \%$ ), (dosis 2: 6 versus 7\%) y enrojecimiento en el sitio de la aplicación (dosis 1: 5 versus 5\%), (dosis 2: 6 versus 7\%), respectivamente. En general, fueron de gravedad leve a moderada y se resolvieron en uno o dos días. ${ }^{8}$

Los principales efectos adversos sistémicos en personas de entre 16 y 55 años, comparando el porcentaje de aparición en la dosis 1 versus 2, fueron: fatiga (47 versus $59 \%$ ), mialgia (21 versus $37 \%$ ), escalofríos (14 versus $35 \%)$, artralgia (11 versus $22 \%$ ), diarrea (11 versus $10 \%$ ), y fiebre (4 versus 16\%). En personas mayores de 55 años, los principales efectos adversos sistémicos, comparando el porcentaje de aparición en la dosis 1 versus 2, fueron: fatiga ( 34 versus $51 \%$ ), cefalea (25 versus $39 \%$ ), mialgia (14 versus $29 \%$ ), escalofríos (6 versus $23 \%$ ), artralgia (9 versus $19 \%)$, y fiebre (1 versus $11 \%){ }^{8}$

ALC-0159, componente que forma parte de las nanopartículas lipídicas, contiene dentro de su conformación un polímero hidrofílico llamado polietilenglicol (PEG), el cual se ha visto implicado en reacciones alérgicas severas y anafilaxia, con una frecuencia muy baja aunque creciente. ${ }^{14}$ Wenande y Garvey ${ }^{15}$ concluyeron que cada sujeto alérgico al PEG posee un nivel de umbral individual dependiente de la cantidad en $\mathrm{g} / \mathrm{mol}$ ingerida. Los síntomas más comunes son prurito, rubor, urticaria, y angioedema, pudiendo progresar a hipotensión, sensación de opresión en el pecho y disnea en casos graves. Se recomienda observar al paciente 30 minutos, tras la administración de BNT162b2, y que cada hospital cuente con una lista de medicamentos de emergencia y acciones a realizar ante un posible suceso. ${ }^{14}$ En caso de desarrollar anafilaxia en la primera aplicación, no se deberá administrar la segunda. ${ }^{16}$ En diciembre de 2020, el Sistema de Notificación de Reacciones Adversas a las Vacunas (VAERS) de Estados Unidos detectó 21 casos de anafilaxia después de la administración de 1,893,360 primeras dosis de BNT162b2 (una tasa de 11.1 casos por millón de dosis). ${ }^{17}$ En Reino Unido, hasta el 23 de diciembre de 2020, fueron registrados dos casos de anafilaxia. ${ }^{18}$

Ninguna mujer embarazada fue incluida en los ensayos clínicos, por razones de seguridad. Sin embargo, debido a que las mujeres embarazadas con COVID-19 tienen mayor riesgo de desarrollar una enfermedad grave, de sufrir eventos adversos y de morir, en comparación con las mujeres no embarazadas en edad reproductiva y las mujeres embarazadas sin el padecimiento, ${ }^{19}$ los CDC, el Comité Asesor sobre Prácticas de Inmunización (ACIP), el Colegio Americano de Obstetras y Ginecólogos (ACOG) y la Academia Americana de Pediatría (AAP), indican que 
las preparaciones contra la afección no deben evitarse en mujeres embarazadas. ${ }^{20}$

Actualmente, existen resultados preliminares de la aplicación de BNT162b2 (Pfizer-BioNTech) en mujeres embarazadas durante el segundo y tercer trimestre principalmente, los datos durante el primer trimestre son escasos. Se encontró que en la vacunación de mujeres embarazadas durante el tercer trimestre existe un cierto grado de protección al neonato, además de conferir protección a las mujeres embarazadas, ya que se evidenció la transferencia transplacentaria de anticuerpos neutralizantes. Las anomalías congénitas no pudieron ser estudiadas, debido a que ninguna de las mujeres embarazadas inyectadas durante las primeras etapas del embarazo ha dado alumbramiento durante el seguimiento. Además, la proporción de féminas embarazadas que tuvieron un aborto espontáneo puede no reflejar las verdaderas proporciones en la población total de embarazadas posteriores a la vacunación. ${ }^{19}$

\section{MODERNA: mRNA-1273}

El 18 de diciembre de 2020, la FDA autorizó la propuesta de Moderna COVID-19 (mRNA-1273) destinada a uso de emergencia, convirtiéndose en la segunda sustancia autorizada en Estados Unidos de América. ${ }^{21}$ El 30 de abril de 2021, mRNA-1273 se convierte en la cuarta vacuna COVID-19 en recibir la autorización de emergencia por la OMS.

Moderna mRNA-1273 es una alternativa basada en ARNm que codifica la proteína espiga (S) del SARS-CoV-2, estabilizada por medio de la sustitución de dos prolinas (2P), dando origen al antígeno S-2P, el cual, buscando evitar su degradación, es encapsulado en nanopartículas lipídicas. ${ }^{22}$

Actualmente, la vacuna se encuentra aprobada únicamente en personas mayores de 18 años, en un esquema que consiste en la administración de dos dosis intramusculares de $0.5 \mathrm{~mL}$ cada una, con un intervalo entre ellas de 28 días.

Una ventaja de mRNA-1273, en comparación con otras alternativas dentro de la misma plataforma, son las temperaturas que requiere para su conservación, las cuales son consideradas fáciles de reproducir. Para su transporte o almacenamiento a largo plazo, la vacuna requiere una temperatura de -25 a $-15^{\circ} \mathrm{C}$; en refrigeración convencional, a una temperatura de 2 a $8^{\circ} \mathrm{C}$, perdura hasta 30 días; a temperatura ambiente de 8 a $25^{\circ} \mathrm{C}$, antes de abrir el vial, tiene una duración de 12 horas, una vez abierto el tiempo se reduce en un $50 \%$, con una vida útil de hasta seis horas. ${ }^{23}$

La propuesta de Moderna contra SARS-Cov-2, mRNA1273, demostró una eficacia de 94.1\% en la prevención de COVID-19 sintomático, 14 días o más después de la segunda dosis, y una eficacia de $100 \%$ en la prevención del trastorno severo, después de la aplicación de ambas inyecciones. En personas de más de 65 años con comorbilidades se observó una eficacia de $86.4 \%{ }^{22}$

El principal efecto adverso local observado en personas de entre 18 y 64 años y mayores de 65 años, fue dolor en el sitio de la inyección (dosis 1: 86.9 versus 74\%), (dosis 2: 90.1 versus $83.4 \%$ ). Los principales efectos adversos sistémicos observados en personas de entre 18 y 64 años y mayores de 65 años fueron: fatiga (dosis 1: 38.5 versus $33.3 \%$ ), (dosis $2: 67.6$ versus $58.4 \%$ ), cefalea (dosis $1: 35.4$ versus $24.5 \%$ ), (dosis $2: 62.8$ versus $46.4 \%$ ) y mialgia (dosis 1: 23.7 versus $19.8 \%$ ), (dosis 2: 61.3 versus $46.9 \%$ ). ${ }^{22}$

Fueron notificados 12 casos de reacciones locales retardadas grandes (COVID Arm), de apariencia variable, localizadas alrededor del sitio de la inyección: placas anulares (un paciente), placas uniformes y edematosas (tres personas), placas induradas (dos personas), placas targetoides (un paciente) y erupciones localizadas en el brazo (dos pacientes), estos últimos además presentaron pápulas urticariales en codos y pápulas en la palma y dedos ipsilaterales, respectivamente. Las reacciones tuvieron un inicio promedio de ocho días (4-11 días) posterior a la aplicación de la primera inyección y una resolución promedio de seis días (2-11 días) después del inicio de las manifestaciones clínicas. Debido a que las reacciones de hipersensibilidad retardada no son consideradas contraindicación para la aplicación de la segunda dosis de mRNA-1273, todos los pacientes completaron su esquema, con los siguientes resultados: $50 \%$ sin recurrencia, $25 \%$ reacciones recurrentes similares a la inicial y $25 \%$ reacciones recurrentes de menor grado, con un inicio promedio de dos días (uno a tres días). La mayoría de los pacientes recibieron tratamiento sintomático (hielo, antihistamínicos o glucocorticoides). ${ }^{24}$

\section{VACUNAS CON VECTORES VIRALES NO REPLICATIVOS}

\section{ASTRA ZENECA: AZD'1222}

En medio de la pandemia por COVID-19, la farmacéutica AstraZeneca, junto con la Universidad de Oxford, desarrolló la vacuna AZD1222 también conocida como ChAdOx1 nCoV-19, la cual utiliza la plataforma vacunal de vectores virales. ${ }^{25}$ El 15 de febrero de 2021 se convierte en la segunda sustancia autorizada por la OMS destinada a uso de emergencia.

Esta alternativa utiliza un vector adenoviral de chimpancé, deficiente en replicación (ChAdOx1), portador del antígeno de glicoproteína de superficie estructural del SARSCoV-2; a diferencia de otras sustancias con la plataforma de vectores, ChAdOx utiliza un vector adenoviral de simio 
a fin de evitar la posible inmunidad preexiste a adenovirus humanos y así garantizar la respuesta inmunológica. ${ }^{26}$

La vacuna se almacena y distribuye en un vial $(5 \mathrm{~mL}$ con 10 dosis o $4 \mathrm{~mL}$ con ocho) el cual puede ser almacenado hasta por seis meses a una temperatura entre 2 y $8{ }^{\circ} \mathrm{C}$. ChAdOx1 nCoV-19 se administra por vía intramuscular (músculo deltoides preferentemente) con un esquema de vacunación de dos partes con diferencia mínima de cuatro y máxima de 12 semanas entre ellas; una vez abierto el vial se debe utilizar dentro de seis horas manteniéndolo a una temperatura entre 2 y $25^{\circ} \mathrm{C}$ durante el uso. ${ }^{27}$ Una ampolleta de la sustancia contiene $0.5 \mathrm{~mL}$ : ChAdOx1-S $5 \times 10^{10}$ partículas virales diluidas. Entre sus excipientes se encuentra polisorbato 80 el cual se ha asociado con reacciones alérgicas, ${ }^{28}$ debido a esto, se recomienda la vigilancia de signos y síntomas dentro de los primeros 15 minutos de la aplicación de la dosis, aquellas personas que desarrollen reacciones alérgicas deberán suspender el esquema de vacunación sin recibir una segunda inyección.

De acuerdo a los resultados obtenidos en cuatro ensayos Clínicos en Brasil, Sudáfrica y Reino Unido, el biológico ChAdOx1 nCoV-19 ha demostrado una eficacia general de $66.7 \%$ para la prevención de la COVID-19 a los 14 días de la segunda dosis, en personas que no habían presentado infección previa y demostraron no haber tenido contacto con el virus. ${ }^{29}$ En los pacientes a quienes se les aplicó una segunda inyección con un periodo más largo (12 semanas), la eficacia fue mayor con un $81.3 \%$, respecto a los pacientes que recibieron una segunda dosis en un tiempo más corto (seis semanas) con una eficacia de $55.1 \%$. La eficacia demostrada contra padecimiento moderado a severo fue de $100 \% .{ }^{30}$ Los datos obtenidos en un estudio fase III realizado en Sudáfrica señalan que la eficacia de esta vacuna contra la variante B.1.351 es del $10.4 \%$, sin efecto en la prevención de la COVID-19 de leve a moderado. ${ }^{31}$

Entre los efectos adversos más comunes reportados en los estudios de seguridad e inmunogenicidad fase I/ II realizados en Reino Unido, resaltan los efectos locales en el sitio de aplicación, donde predominan: dolor con un porcentaje de aparición del 30\% en personas de 18 a 55 años y $10 \%$ en mayores de 70 años, enrojecimiento y calor con un $7 \%$ de aparición en general e hinchazón con un $2 \%$ sólo en personas mayores de 70 años. Al igual que los efectos locales, el porcentaje de aparición de efectos sistémicos varía, dependiendo del rango de edad, siendo la población de entre 18 y 55 años la que reporta una mayor tasa de incidencia. Entre los efectos sistémicos que se reportan destacan: fatiga, cefalea, mialgia, escalofríos, artralgia, y fiebre. ${ }^{32}$

En febrero de 2021, se reportó un nuevo evento adverso asociado a la aplicación de esta mixtura, conocido como síndrome de trombosis trombocitopénica (TTS) el cual incluye eventos graves en la coagulación. La trombosis en sitios específicos (cerebro y abdomen) es una característica principal de la TTS, por lo que se recomienda una monitorización, reconocimiento y reporte de cefaleas, o dolor abdominal grave y persistente, con aparición entre los cuatro y 20 días posteriores a la vacunación. ${ }^{33}$ Los datos proporcionados por el Reino Unido estiman que el riesgo aproximado es de cuatro casos por millón de adultos (un caso por 250,000).

Es importante señalar que los resultados obtenidos no incluyen a mujeres embarazadas, ni menores de edad, por lo que no se recomienda la aplicación de esta sustancia en esa población; aunque esta situación no contraindica la aplicación de la vacuna, se deberá evaluar el riesgo beneficio para la aplicación en mujeres embarazadas y niños. La única contraindicación existente actualmente es la existencia de historial de alergia a algún componente.

\section{Centro Nacional de Gamaleya: Sputnik V}

En junio de 2020, el Centro Nacional Gamaleya informó que se encontraba en desarrollo una vacuna experimental para la prevención de la enfermedad, dos meses después fue aprobada para su uso y aplicación de emergencia en Rusia. Actualmente, se encuentra aprobada en 60 países, entre ellos Argentina y México, además de la realización de un estudio de fase III el cual se lleva a cabo en los Emiratos Árabes Unidos, India, Venezuela y Bielorrusia. ${ }^{34}$

Gam-COVID-Vac se basa en el uso de vectores adenovirales recombinantes para la introducción de la secuencia de ARN de la proteína espiga del nuevo SARS-CoV-2 en las células hospederas. A diferencia de otras sustancias de la misma plataforma vacunal, este biológico utiliza dos vectores adenovirales recombinantes humanos diferentes, rAd26 y rAd5, los cuales portan la cadena larga del gen de la glicoproteína S del SARS-CoV-2. ${ }^{35}$

La propuesta Sputnik V se distribuye en viales multidosis, los cuales contienen $3 \mathrm{~mL}$ de la vacuna correspondientes a 5 dosis (0.5 mL por cada una). Los viales se encuentran empaquetados y diferenciados por código de color y número, a fin de garantizar el orden de aplicación, siendo la primera correspondiente al vector $\mathrm{rAd} 26-\mathrm{S}$ y la segunda al rAd5-S, ambas inyecciones se aplican vía intramuscular con 21 días de diferencia. La sustancia se almacena congelada a una temperatura de $-18^{\circ} \mathrm{C}$ y puede mantenerse durante tres meses en lugares oscuros. Una vez descongelada, deberá ser usada dentro de las primeras dos horas y no volverse a congelar. ${ }^{36}$ Ambas dosis cuentan con el mismo excipiente el cual, entre otras partículas, contiene polisorbato 80, presente en diferentes vacunas, por lo que se recomienda evitar la aplicación en personas que hayan presentado reacciones alérgicas a este componente. ${ }^{36}$ 
La eficacia demostrada en un estudio multicéntrico fase III realizado en Rusia, para la prevención de la COVID-19 por la Gam-COVID-Vac en adultos mayores a 18 años, fue de $91.6 \%$ al día 21 después de la segunda dosis, la eficacia reportada a los 14 días previos de la primera dosis fue de $73.1 \%$, incrementando con la segunda dosis al $91.1 \%$ después de 28 días de la primera aplicación. Es importante señalar que se reportó un 100\% de eficacia en la prevención de los casos graves del padecimiento. No se han encontrado diferencias significativas en cuanto a sexo y edad. ${ }^{36}$

Los estudios de inmunogenicidad y seguridad fases I y II realizados en Rusia revelaron que es bien tolerada en personas mayores de 18 años. Su principal efecto adverso fue la enfermedad similar a la gripe $(15.2 \%) ; 35$ los resultados adversos hallados en estudios de fase III son: reacciones locales en el sitio de aplicación (5.4\%), cefalea (2.9\%), y astenia (2.5\%), todos reportados de intensidad moderada y con desaparición en 24 horas posteriores a la vacunación; en personas adultas mayores de 60 años las principales reacciones adversas son: reacciones locales (15.2\%), astenia (5.4\%), hipertensión (3.9\%), dermatitis de contacto (3.8\%), dolor de cabeza (2.9\%), fiebre (2.2\%). ${ }^{36}$ No se ha asociado la aplicación de esta mezcla con efectos sistémicos graves, actualmente existen protocolos de investigación que logran la monitorización y reporte de efectos adversos graves.

Ya que no existe evidencia sobre la seguridad de esta vacuna en menores de edad y mujeres embarazadas, buscando evitar posibles riesgos, se recomienda no utilizarla en esta población.

\section{CANSINOBIO: AD5-NCOV}

En marzo de 2020, CanSino, sustancia que utiliza el vector de adenovirus humano no replicante tipo cinco (Ad5), comenzó con ensayos clínicos fase I. Dicha vacuna es desarrollada por el Instituto de Biotecnología de Beijing y CanSino Biologics, ambos laboratorios con sede en China. Esta propuesta expresa la glicoproteína de espiga del SARS-CoV-2 e induce respuesta inmune celular y humoral, generando anticuerpos neutralizantes específicos para la proteína S del SARS-CoV-2. ${ }^{37,38}$

Actualmente, se dispone de dos presentaciones: dosis única o multidosis, las cuales cuentan con el principio activo adenovirus no replicante, Ad5-nCoV, en una concentración de aproximadamente $4 \times 10^{10}$ partículas virales, éstas se pueden mantener por 12 meses en refrigeración a una temperatura entre 2 y $8^{\circ} \mathrm{C}$.

A diferencia de otras vacunas que utilizan la misma plataforma, esta preparación se administra vía intramuscular en esquema monodosis de $0.5 \mathrm{~mL} .^{38}$

Los resultados de los ensayos de fase II realizados en China, revelan que el biológico tiene una eficacia general a los 14 días de la aplicación del $68.3 \%$ en la prevención de la COVID-19. En especial, la vacuna cuenta con una eficacia de $95.4 \%$ para la prevención de la enfermedad grave a los 14 días y $90.07 \%$ a los 28 días. ${ }^{38}$ En este momento, no se encuentran disponibles más datos sobre la eficacia de esta alternativa, pero no se han encontrado diferencias significativas entre grupos de edad y sexo. Este estudio también demostró que en personas que han estado en contacto con el vector (Ad5) la efectividad ha sido menor, comparada con la respuesta generada en personas que no han tenido exposición con dicho vector. ${ }^{38}$

Los estudios de seguridad fases I y II demostraron que, en general, es bien tolerada en personas sanas, la reacción adversa local más común fue dolor en el sitio de la inyección (56\%), mientras que los efectos adversos sistémicos que más se reportaron fueron: fatiga (34\%), cefalea (28\%), mialgias (18\%) fiebre (16\%), y artralgias (13\%). La aparición de efectos adversos ocurrió durante las primeras 24 horas después de la vacunación. ${ }^{38}$

\section{Janssen (Johnson \& Johnson): Ad26.COV2.S}

El 12 de marzo de 2021, la Organización Mundial de la Salud (OMS) agrega a su lista de aprobaciones de uso de emergencia contra SARS-CoV-2 a la sustancia fabricada por la farmacéutica Janssen, Ad26.COV2.S, siendo la tercera vacuna en recibir la validación, pero convirtiéndose en la primera con esquema monodosis. ${ }^{39}$

Ad26.COV2.S es una alternativa creada por Johnson \& Johnson, la cual está compuesta por un vector de adenovirus humano tipo 26 (Ad26) de replicación incompetente, que codifica una variante de la proteína $S$ de longitud completa estabilizada por medio de mutaciones. ${ }^{40}$

La vacuna Ad26.COV2.S está disponible en un vial de dosis múltiple (5 de $0.5 \mathrm{~mL}$ cada una). Actualmente, únicamente está autorizada en personas mayores de 18 años $y$, a diferencia de la mayoría de las otras, se administra en un esquema de dosis única de $0.5 \mathrm{~mL}$ vía intramuscular, debido a que en la fase I/II, demostró generar $90 \%$ de anticuerpos neutralizantes al día 29 después de la primera dosis. ${ }^{40}$ Para su almacenamiento, los viales multidosis sin perforar requieren estar a temperatura de entre 2 y $8^{\circ} \mathrm{C}$; sin embargo, son capaces de resistir hasta 12 horas a temperaturas entre 9 y $25^{\circ} \mathrm{C}$. Una vez perforado el vial, en caso de no utilizarse por completo, es capaz de resistir hasta seis horas a temperaturas entre 2 y $8^{\circ} \mathrm{C}$; a temperatura ambiente, máximo a $25^{\circ} \mathrm{C}$, es capaz de durar hasta dos horas. ${ }^{41}$

La eficacia de Ad26.COV2.S contra COVID-19 moderada a grave, en casos ocurridos 14 días después de la vacunación, fue de $66.9 \%$; para sucesos ocurridos 28 días después de la campaña fue de $66.1 \%$. En el padecimiento grave, la eficacia fue de $76.7 \%$ en casos ocurridos 
14 días después de la inyección; para casos ocurridos 28 días después de la vacunación fue de $85.4 \%$. En pacientes mayores de 60 años con comorbilidades, la eficacia para COVID-19 de severidad moderada a grave fue de $64.9 \%$, 14 días después de la campaña, y de 42.3\%, 28 días después de la vacunación. ${ }^{42}$

En la fase III del estudio COV3001, se encontró una eficacia contra la variante de Brasil de $66.2 \%$ al día 14 y de $68.1 \%$ al día 28 , después de la vacunación para afección de moderada a grave. La eficacia fue de $81.9 \%$ al día 14 y de $87.6 \%$ al día 28 para el trastorno grave. En el caso de la variante sudafricana, se encontró una eficacia de $52 \%$ al día 14 y de $64 \%$ al día 28, después de la vacunación para COVID-19 de moderada a grave. La eficacia fue de $73.1 \%$ al día 14 y de $81.7 \%$ al día 28 para padecimiento grave. ${ }^{40}$

El principal efecto adverso local registrado fue dolor en el sitio de la inyección (48\%). Los resultados adversos sistémicos más comunes fueron cefalea $(38.9 \%)$, fatiga $(38.2 \%)$, mialgias $(33.2 \%)$, y náuseas $(14.2 \%) .{ }^{40}$

El 13 de abril de 2021, la CDC y la FDA detuvieron la administración de Ad26.COV2.S, luego de la aparición de seis casos de trombosis trombocitopénica notificados en Estados Unidos de América, los cuales se produjeron entre el día siete y 14 después de la campaña, sin embargo, estos casos fueron notificados entre más de 7.2 millones de personas que habían sido vacunadas con Ad26.COV2.S a nivel mundial al 14 de abril de 2021, demostrando una tasa de incidencia de menos de 1 en 1,000,000 de vacunaciones. ${ }^{43}$ El 23 de abril de 2021, el Comité Asesor sobre Prácticas de Inmunización (ACIP) y la CDC, en conjunto con la FDA, toman la decisión de reanudar el uso de Ad26.COV2.S. ${ }^{44}$ En el presente, la incidencia actualizada es de 2/1,000,000 con 15 casos reportados luego de 7.98 millones de dosis administradas. ${ }^{45}$

\section{VACUNAS CON VIRUS VIVOS INACTIVADOS O ATENUADOS}

\section{SINOVAC: CORONAVAC}

CoronaVac es una vacuna contra la COVID-19, de virus inactivados, desarrollada por la compañía farmacéutica China Sinovac Biotech. El primero de junio de 2021 es considerada la sexta marca con aprobación de la OMS para su uso de emergencia. Esta formulación contiene el SARSCoV-2 (cepa CN02), el cual se propagó en células de riñón de mono verde africano y se inactivó con $\beta$-propiolactona, se concentró, se purificó y finalmente se absorbió con hidróxido de aluminio. ${ }^{46}$ El virus inactivado ha perdido la capacidad de inducir la enfermedad, pero se conserva su potencial de inducir una respuesta inmune específica frente al SARS-CoV-2, no sólo contra la proteína S "Spike" también conocida como proteína pico o espiga), sino contra otras moléculas presentes en este agente infeccioso. ${ }^{47} \mathrm{La}$ sustancia en forma líquida se presenta en frasco ámpula de una dosis de $0.5 \mathrm{~mL}$ o en jeringa prellenada de 0.5 $\mathrm{mL} .{ }^{46}$ No se incluyen conservantes en su formulación. Su conservación debe mantenerse de 2 a $8^{\circ} \mathrm{C}$, la cual puede mantenerse a esa temperatura por un periodo de hasta seis meses desde su producción. Se administra vía IM en la región deltoidea del brazo de menor uso, en un esquema de dos dosis de $0.5 \mathrm{~mL}$ cada una, con un intervalo de cuatro semanas entre ambas, primera inyección (o día cero), y la segunda aplicación a partir del día $28 .{ }^{46}$

De acuerdo con estudios de fase III de la marca CoronaVac realizados en Turquía, utilizando dosis de $3 \mu \mathrm{g}$, la eficacia para la prevención de casos confirmados después de la segunda parte fue de $91.25 \% .^{48}$ En un estudio realizado en Brasil en 53,176 trabajadores de la salud de más de 18 años de edad, se evaluó la eficacia de la vacuna CoronaVac en presencia de la variante P1 (brasileña) encontrando una disminución en la eficacia de la misma a $49.6 \%$ en un entorno de alta prevalencia de la variante P1. ${ }^{49}$

Los eventos adversos de esta vacuna, de acuerdo con el ensayo fase III, mayormente fueron de tipo no grave y pueden desarrollarse en el transcurso del primer o segundo día después de la vacunación. ${ }^{46}$ Los más frecuentes fueron las reacciones locales (39.0\%): dolor en el sitio de aplicación, exantema, eritema, induración, mialgias, y reacciones sistémicas (45.7\%): cefalea, fatiga, mialgias, fiebre, diarrea, escalofríos. ${ }^{46}$

Las contraindicaciones absolutas de esta sustancia son: pacientes que recientemente hayan presentado COVID-19 y aún no se recuperen, individuos que hayan recibido plasma convaleciente previo a la vacunación (diferir 90 días la vacunación contra SARS-CoV-2), y pacientes con alergia conocida a algún componente de la vacuna o reacción alérgica grave a dosis anteriores. ${ }^{50}$ No se tiene información sobre la vacunación en menores de 18 años y mujeres embarazadas, por lo que por ahora esta población no será incluida en la vacunación rutinaria. ${ }^{50}$ Las personas infectadas con el virus de la inmunodeficiencia humana $(\mathrm{VIH})$ con buen control se pueden vacunar, aunque la respuesta inmune podría ser limitada o inferior a la presentada por personas que no viven con este virus. ${ }^{51}$

\section{SINOPHARM: BBIBP-COrV}

La propuesta de Sinopharm BBIBP-CorV fue desarrollada en colaboración con el Beijing Institute of Biological Products. ${ }^{52}$ Consiste en una vacuna inactivada (cepa HB02), la cual fue cultivada y purificada en células Vero, posteriormente fue inactivada mediante su mezcla completa con $\beta$-propiolactona. ${ }^{52}$ Se presenta como una solución 
para inyección intramuscular, lista para su uso en un vial con monodosis de $0.5 \mathrm{~mL}$. El vial debe conservarse a temperaturas de refrigeración $\left(2\right.$ a $\left.8^{\circ} \mathrm{C}\right)$, no se debe congelar y tiene que estar protegido de la luz. ${ }^{52}$ Se administra vía intramuscular, en un esquema de dos dosis de $0.5 \mathrm{~mL}$ con 21-28 días interdosis.

De acuerdo con un ensayo realizado en Emiratos Árabes Unidos, la vacuna mostró una eficacia de $86 \%$ para la enfermedad sintomática y $100 \%$ de eficacia para la enfermedad grave. ${ }^{53}$ Sin embargo, el resultado preliminar arrojado por el estudio fase III realizado en Argentina, mostró una eficacia de $79.34 \%$ para prevenir la enfermedad por SARS-CoV-2. ${ }^{54}$

Los efectos adversos fueron de gravedad leve o moderada y se desarrollaron durante los primeros siete días después de la inoculación. Los efectos adversos locales fueron los siguientes: dolor en el sitio de la inyección (> $10 \%)$; eritema, hiperemia, prurito, edema o hinchazón en el sitio de la inyección (1-10\%), y rash cutáneo en el sitio de la inyección $(<1 \%) .{ }^{52}$ Los efectos adversos sistémicos observados fueron: fatiga, fiebre transitoria, cefalea, diarrea, tos, y disnea (1-10\%), así como náuseas, vómitos, mialgias, artralgias, somnolencia, mareos, anorexia $(<$ $1 \%)$. Se recomienda el uso del AINE paracetamol ante la aparición de fiebre después de la vacunación. ${ }^{52}$

Las contraindicaciones de esta alternativa son: pacientes que recientemente hayan presentado COVID-19 y aún no se recuperen, individuos que hayan recibido plasma convaleciente previo a la vacunación (diferir 90 días la vacunación contra SARS-CoV-2) y pacientes con alergia conocida a algún componente de la vacuna o reacción alérgica grave a la dosis anterior. Se debe tener precaución en pacientes con trombocitopenia y trastornos de la coagulación, y epilepsia no controlada u otro trastorno neurológico progresivo. ${ }^{54}$

\section{COVAXIN: BBV152}

Vacuna de la India, BBV152, a base de virus inactivados, creada por Bharat Biotech que se desarrolla en colaboración con el Consejo Indio de Investigación Médica (ICMR)Instituto Nacional de Virología (NIV). La preparación utiliza tecnología de plataforma derivada de virus completo inactivado a partir de cultivo de células Vero. ${ }^{55}$ Se requiere la aplicación vía intramuscular de dos dosis de $0.5 \mathrm{~mL}$, con un intervalo de 28 días. Cada ampolleta debe permanecer a una temperatura de entre 2 y $8^{\circ} \mathrm{C} .^{55}$

De acuerdo con su estudio fase III en desarrollo, COVAXIN demostró una eficacia provisional de $81 \%$ en la prevención de la enfermedad en aquellos sin infección previa después de la segunda dosis. ${ }^{55}$ De acuerdo con reportes de Bharat Biotech, los anticuerpos inducidos por la marca COVAXIN pueden neutralizar las cepas variantes del Reino Unido. ${ }^{55}$
Los efectos secundarios que se han informado por Bharat Biotech COVID-19 (COVAXIN) incluyen: dolor, hinchazón, eritema y prurito en el lugar de la inyección (2\%); cefalea $(1 \%)$, fiebre (2\%), malestar general (2\%); mialgias, náusea, vómitos, y erupciones. ${ }^{55}$ No se recomienda la administración de esta vacuna en pacientes con alergia conocida a algún componente de la vacuna. Las mujeres embarazadas y madres lactantes no deben recibir la vacuna, ya que no se ha estudiado el efecto en esta población. Los pacientes con VIH y receptores de trasplantes pueden tener una respuesta inmunitaria debilitada en comparación con la población general. ${ }^{55}$

\section{VACUNAS CON SUBUNIDADES PROTEICAS}

\section{NOVAVAX: NVX-CoV2373}

La vacuna NVX-CoV2373, desarrollada por el laboratorio Novavax, utiliza la proteína S del SARS-CoV-2 junto con un adyuvante Matrix-M1, además, mediante nanopartículas recombinantes, genera una mutación en los sitios de escisión S1 y S2, lo que confiere resistencia a la proteasa.

La vacuna, así como el adyuvante, se almacenan a una temperatura entre 2 y $8^{\circ} \mathrm{C}$, facilitando su transporte y distribución. Novavax se administra en un esquema de dos dosis, ambas separadas por 21 días (primera dosis $5-\mu g$ y segunda parte $25 \mu \mathrm{g}$ ), por vía intramuscular. ${ }^{56}$

Actualmente, se encuentra en proceso un estudio de fase III en Reino Unido para evaluar la eficacia de esta vacuna, datos preliminares señalan que la sustancia cuenta con un $96 \%$ de eficacia contra la cepa original y un $86 \%$ contra la variante B.1.1.7..$^{56}$

Se ha demostrado que al día 21 se produce una respuesta inmunitaria después de la aplicación de esta vacuna, una sola dosis alcanza valores de medias geométricas anti-Spike IgG (GMEU) parecidas a los de pacientes asintomáticos de COVID-19, mientras que una segunda inyección con adyuvante alcanza niveles mayores a los encontrados en suero convaleciente de pacientes sintomáticos. ${ }^{57}$

Los resultados preliminares obtenidos en el estudio de fase III realizado en Reino Unido reportan al dolor como el efecto local más común (37\%) después de recibir una dosis. Los efectos adversos sistémicos reportados después de la primera y segunda dosis fueron cefalea (20-25\%), mialgias (17-20\%), y fatiga (12-16\%), la duración de dichos eventos fue más larga después de la segunda dosis, pero menor de tres días. ${ }^{57}$

Se han encontrado alteraciones en estudios de laboratorio, entre las que destaca la disminución transitoria de hemoglobina ( $5 \%$ de los casos) con resolución dentro de los siete a 21 días posteriores. ${ }^{58}$ 
La única contraindicación actual para esta vacuna es la existencia de alergia a alguno de los componentes, los resultados en estudios controlados no reflejan a la población femenina al momento del embarazo y a menores de edad, por lo que se recomienda evitar la aplicación en estas poblaciones.

\section{CONCLUSIÓN}

Las vacunas contra la COVID-19 que se encuentran actualmente en aplicación han mostrado una inmunogenicidad prometedora con un grado variable de eficacia contra el desarrollo de la enfermedad moderada o severa, así como un perfil de seguridad aceptable. La administración de segundas dosis de inmunización proporciona una respuesta inmunológica más robusta en todas las vacunas y para situaciones de emergencia la OMS ha aceptado el uso de seis de ellas hasta la fecha.

En vista del aumento de infecciones ocasionadas por la pandemia, y de la prometedora eficacia de las vacunas en las diferentes etapas de los ensayos clínicos, la mayoría de los países han desarrollado programas de vacunación para sus ciudadanos. Sin embargo, se han planteado dudas sobre la eficacia contra las nuevas variantes del SARS-CoV-2 de preocupación como la británica, brasileña, sudafricana y posiblemente la variante de interés de la India (B.1.617.1/2); por lo que se necesitan mayores estudios para determinar su eficacia. Otro problema es el desconocimiento de la duración de las eficacias protectoras de las vacunas para detener la transmisión de las cepas virales, tanto previas como nuevas; así como la presencia de anticuerpos neutralizantes protectores contra la infección por SARS-CoV-2 a través de las vacunas de aplicación intranasal y subdérmica. Sin embargo, es importante la continuación de medidas protectoras y preventivas en la población, ya que la reinfección sigue siendo potencialmente posible. Este proceso en la generación de vacunas está en un continuo cambio y renovación en el tiempo, en el que se espera la mitigación de la pandemia por la COVID-19.

Conflicto de intereses: Todos los autores declaran que no presentan conflicto de intereses.

\section{REFERENCIAS}

1. Organización Mundial de la Salud. OMS: Declaración COVID-19: Cronología de la respuesta de la OMS a la COVID-19]. (Modificado 29 Ene 2021; Consultado 07 may 2021). Disponible en: https://www. who.int/es/news/item/29-06-2020-covidtimeline

2. GAVI The Vaccine Alliance. COVAX: The COVID-19 vaccine raceweekly update. (Modified 03 Jun 2021; consulted 03 Jun 2021). Available in: https://www.gavi.org/vaccineswork/covid-19-vaccinerace\#phases
3. Organización Panamericana de la Salud. OPS: COVID-19 Fases de desarrollo de una vacuna. Mayo 2020. Available in: https://www. paho.org/es/documentos/covid-19-fases-desarrollo-vacuna

4. Organización Mundial de la Salud. OMS: Vacunas e inmunización: ¿qué es la vacunación? (Modificado 30 Dic 2020; consultado 07 mayo 2021). Disponible en: https://www.who.int/es/news-room/qa-detail/vaccines-and-immunization-what-is-vaccination?adgroup survey $=\{$ adgroupsurvey $\}$ \&clid $=$ Cj0KCQjws-OEBhCkARIsAPhO kIZ5WDg3D0mDZ403Dsf_82gwKuayCas-VEYE3IWNOMNWGgdAciTIOYaAnr2EALw_wcB

5. GAVI The Vaccine Alliance. There are four types of COVID-19 vaccines: here's how they work. Available in: https://ww.gavi.org/ vaccineswork/there-are-four-types-covid-19-vaccines-heres-howthey-work

6. Lamb YN. BNT162b2 mRNA COVID-19 vaccine: first approval. Drugs. 2021; 81: 495-501. doi: 10.1007/s40265-021-01480-7.

7. Pardi N, Weissman D. Development of vaccines and antivirals for combating viral pandemics. Nat Biomed Eng. 2020; 4: 1128-1133. doi: 10.1038/s41551-020-00658-w.

8. Pfizer-BioNTech COVID-19 Vaccine (BNT162, PF-07302048) Vaccines and Related Biological Products Advisory Committee. Briefing document. Meeting date: 10 December 2020.

9. Polack FP, Thomas SJ, Kitchin N, Absalon J, Gurtman A, Lockhart S et al. Safety and efficacy of the BNT162b2 mRNA COVID-19 vaccine. N Engl J Med. 2020; 383: 2603-2615. doi: 10.1056/NEJMoa2034577.

10. Naik R, Smith M, Gottschalk L, Wollersheim S, Lee L, Huang L et al. Pfizer-BioNTech COVID-19 Vaccine EUA amendment review memorandum. Available in: https://www.fda.gov/media/148542/ download

11. Centros para el Control y la Prevención de Enfermedades. Visión general y seguridad de la vacuna contra el COVID-19 de PfizerBioNTech [Internet]. 21 de mayo de 2021 [Consultado 25/05/2021]. Disponible en: https://espanol.cdc.gov/coronavirus/2019-ncov/ vaccines/different-vaccines/Pfizer-BioNTech.html

12. Dagan N, Barda N, Kepten E, Miron O, Perchik S, Katz MA et al. BNT162b2 mRNA COVID-19 vaccine in a nationwide mass vaccination setting. N Engl J Med. 2021; 384 (15): 1412-1423. doi: 10.1056/NEJMoa2101765

13. Abu-Raddad LJ, Chemaitelly H, Butt AA. Effectiveness of the BNT162b2 Covid-19 vaccine against the B.1.1.7 and B.1.351 variants. N Engl J Med. 2021; doi: 10.1056/NEJMc2104974

14. Sellaturay P, Nasser S, Ewan P. Polyethylene glycol-induced systemic allergic reactions (Anaphylaxis). J Allergy Clin Immunol Pract. 202; 9 (2): 670-675. doi: 10.1016/j.jaip.2020.09.029.

15. Wenande E, Garvey LH. Immediate-type hypersensitivity to polyethylene glycols: a review. Clin Exp Allergy. 2016; 46: 907-922. doi: 10.1111/cea.12760

16. European Medicines Agency. Covid-19 mRNA vaccine (Comirnaty): EU summary of product characteristics. [Accessed 24 Apr 2021] 2020. Available in: http:// ec.europa.eu

17. CDC COVID-19 Response Team, Food and Drug Administration. Allergic reactions including anaphylaxis after receipt of the first dose of Pfizer-BioNTech COVID-19 vaccine-United States, December 14-23, 2020. MMWR Morb Mortal Weekly Rep. 2021; 70 (2): 46-51. doi: $10.15585 / \mathrm{mmwr} . \mathrm{mm} 7002 \mathrm{e} 1$.

18. Jop de Vrieze. Pfizer's vaccine raises allergy concerns. Science. 2021; 371 (6524): 10-11. doi: 10.1126/science.371.6524.10

19. Shimabukuro TT, Kim SY, Myers TR, Moro PL, Oduyebo T, Panagiotakopoulos L et al. Preliminary Findings of mRNA Covid-19 vaccine safety in pregnant persons. N Engl J Med. 2021. doi: 10.1056/ NEJMoa2104983.

20. Centers for Disease Control and Prevention. COVID-19 vaccines: interim clinical considerations for use of COVID-19 vaccines currently authorized in the United States. 2021. Available in: https://www.cdc. gov/vaccines/covid-19/info-by-product/clinical-considerations.html 
21. Oliver SE, Gargano JW, Marin M et al. The Advisory Committee on Immunization Practices' Interim Recommendation for Use of Moderna COVID-19 Vaccine-United States. 2020. MMWR Morb Mortal Wkly Rep. 2021; 69 (51-52): 1653-1656. doi: 10.15585/ mmwr.mm695152e1.

22. Zhang R. Vaccines and related biological products advisory committee meeting presentation. (17 December 2020). MRNA-1273. USA: Moderna.

23. MRNA-1273 Sponsor Briefing Document Vaccines And Related Biological Products Advisory Committee Meeting Date, 17 December 2020, Available in: https://www.fda.gov/media/144452/download

24. Blumenthal KG, Freeman EE, Saff RR, Robinson LB, Wolfson AR, Foreman RK. Delayed large local reactions to mRNA-1273 Vaccine against SARS-CoV-2. N Engl J Med. 2021; 384 (13): 1273-1277. doi: 10.1056/NEJMc2102131.

25. Folegatti PM, Ewer KJ, Aley PK, Angus B, Becker S, Belij-Rammerstorfer $\mathrm{S}$ et al. Safety and immunogenicity of the ChAdOx1 nCoV-19 vaccine against SARS-CoV-2: a preliminary report of a phase 1/2, single-blind, randomised controlled trial. Lancet. 2020; 396 (10249): 467-478. Available in: https://doi.org/10.1016/s0140-6736(20)31604-4

26. Ramasamy MN, Minassian AM, Ewer KJ, Flaxman AL, Folegatti PM, Owens DR et al. Safety and immunogenicity of ChAdOx1 nCoV-19 vaccine administered in a prime-boost regimen in young and old adults (COV002): a single-blind, randomised, controlled, phase $2 / 3$ trial. Lancet. 2021; 396 (10267): 1979-1993. Available in: https:// doi.org/10.1016/s0140-6736(20)32466-1

27. Ema.europa-eu. [Citado el 5 de mayo de 2021]. Disponible en: http:// www.ema.europa-eu/en/documents/product-information-of-covid19-vaccine-astrazeneca-product-information-approved-chmp-29january-2021-pending-endorsement en-pdf

28. Castells MC, Phillips EJ. Maintaining safety with SARS-CoV-2 vaccines. N Engl J Med. 2021; 384 (7): 643-649. Available in: https://doi. org/10.1056/nejmra2035343

29. Voysey M, Clemens SAC, Madhi SA, Weckx LY, Folegatti PM, Aley PK et al. Safety and efficacy of the ChAdOx1 nCoV-19 vaccine (AZD1222) against SARS-CoV-2: an interim analysis of four randomised controlled trials in Brazil, South Africa, and the UK. Lancet. 2021; 397 (10269): 99-111. Available in: https://doi. org/10.1016/s0140-6736(20)32661-1

30. Voysey M, Costa Clemens SA, Madhi SA, Weckx LY, Folegatti PM, Aley PK et al. Single-dose administration and the influence of the timing of the booster dose on immunogenicity and efficacy of ChAdOx1 nCoV-19 (AZD1222) vaccine: a pooled analysis of four randomised trials. The Lancet. 2021; 397 (10277): 881-891. Available in: https:// doi.org/10.1016/s0140-6736(21)00432-3

31. Madhi SA, Baillie V, Cutland CL, Voysey M, Koen AL, Fairlie L et al. Efficacy of the ChAdOx1 nCoV-19 Covid-19 vaccine against the B.1.351 variant. N Engl J Med 2021; 384:1885-1898. Available in: http://dx.doi.org/10.1056/NEJMoa2102214

32. Medicines and Healthcare products Regulatory Agency. UK regulator confirms that people should continue to receive the COVID-19 vaccine AstraZeneca [Internet]. GOV.UK. 2021 [Cited May 5, 2021]. Available in: https://www.gov.uk/government/news/uk-regulator-confirmsthat-people-should-continue-to-receive-the-covid-19-vaccineastrazeneca

33. Europa.eu. [Cited May 5, 2021]. Available in: https://www.ema. europa.eu/en/news/meeting-highlights-pharmacovigilance-riskassessment-committee-prac-6-9-april-2021

34. The first registered COVID-19 vaccine [Internet]. Sputnikvaccine. com. [Cited May 5, 2021]. Available in: https://sputnikvaccine.com/

35. Logunov DY, Dolzhikova IV, Zubkova OV, Tukhvatulin AI, Shcheblyakov DV, Dzharullaeva AS et al. Safety and immunogenicity of an rAd26 and rAd5 vector-based heterologous prime-boost COVID-19 vaccine in two formulations: two open, non-randomised phase 1/2 studies from Russia. Lancet. 2020; 396 (10255): 887-897.
36. Logunov DY, Dolzhikova IV, Zubkova OV, Tukhvatulin AI, Shcheblyakov DV, Dzharullaeva AS. Safety and efficacy of an rAd26 and rAd5 vector-based heterologous prime-boost COVID-19 vaccine: an interim analysis of a randomised controlled phase 3 trial in Russia. Lancet. 2020; 396 (10255): 887-897. Published online Feb 2. Available in: http://dx.doi.org/10.1016/S0140-6736(21)00234-8

37. Zhu F-C, Guan X-H, Li Y-H, Huang J-Y, Jiang T, Hou L-H et al. Immunogenicity and safety of a recombinant adenovirus type-5vectored COVID-19 vaccine in healthy adults aged 18 years or older: a randomised, double-blind, placebo-controlled, phase 2 trial. Lancet. 2020; 396 (10249): 479-488. Available in: https://doi.org/10.1016/ s0140-6736(20)31605-6

38. Zhu FC, Li YH, Guan XH, Hou LH, Wang WJ, Li JX et al. Safety, tolerability, and immunogenicity of a recombinant adenovirus type-5 vectored COVID-19 vaccine: a dose-escalation, openlabel, non-randomised, first-in-human trial. Lancet. 2020; 395 (10240): 1845-1854. Available in: https://doi.org/10.1016/s01406736(20)31208-3

39. Organización Mundial de la Salud. La OMS añade la vacuna de Janssen a la lista de herramientas eficaces y seguras contra la COVID-19 [Internet]. Ginebra: Comunicado de prensa; 12 de marzo de 2021. [Consultado 5 mayo 2021]. Disponible en: https://www.who.int/es/ news/item/12-03-2021-who-adds-janssen-vaccine-to-list-of-safeand-effective-emergency-tools-against-covid-19\#: : :text $=$ La\%20 Organizaci\%C3\%B3n\%20Mundial\%20de\%20la,el\%20marco\%20 del\%20Mecanismo\%20COVAX

40. Janssen Biotech Inc. VRBPAC Briefing Document. 26 Feb 2021, Available in: https://www.fda.gov/media/146219/download

41. Janssen Biotech, Inc. Fact sheet for healthcare providers administering vaccine (vaccination providers). Last updated: April/23/2021. Available in: https://www.janssenlabels.com/emergency-useauthorization/Janssen +COVID-19+Vaccine-HCP-fact-sheet.pdf

42. Sadoff J, Gray G, Vandebosch A, Cárdenas V, Shukarev G, Grinsztejn $B$ et al. Safety and efficacy of single-dose Ad26.COV2.S Vaccine against Covid-19. N Engl J Med. 2021; 384: 2187-2201. Available in: https://www.nejm.org/doi/full/10.1056/NEJMoa2101544

43. Johnson \& Johnson. Johnson \& Johnson Statement on COVID-19 Vaccine (Updated) [Internet]. New Brunswick NJ: Statement; April 13, 2021. [Accessed 5 Apr 2021]. Available in: https://www.jnj.com/ johnson-johnson-statement-on-covid-19-vaccine-updated

44. Johnson \& Johnson. Johnson \& Johnson Statement on April 23 CDC Advisory Committee Meeting on Company COVID-19 Vaccine [Internet]. NEW BRUNSWICK, N.J: Statement; April 23, 2021. [Accessed 5 Apr 2021]. Available in: https://www.jnj.com/johnsonjohnson-statement-on-april-23-cdc-advisory-committee-meeting-oncompany-covid-19-vaccine

45. Bussel J, Connors J, Cines D. Thrombosis with Thrombocytopenia Syndrome - Hematology.org [Internet]. Hematology.org. Last updated 23 Apr 2021, [cited 06 May 2021]. Available in: https://www. hematology.org/covid-19/vaccine-induced-immune-thromboticthrombocytopenia

46. Zhiwei $\mathrm{Wu}$, Yaling Hu, Miao Xu, Zhen Chen, Wanqi Yang, Zhiwei Jiang et al. Safety, tolerability, and immunogenicity of an inactivated SARS-CoV-2 vaccine (CoronaVac) in healthy adults aged 60 years and older: a randomised, double-blind, placebo-controlled, phase $1 / 2$ clinical trial. Lancet. 03/02/2021. Available in: https://www.thelancet. com/journals/laninf/article/PIIS1473-3099(20)30987-7/fulltext

47. Centers for Disease Control and Prevention. Epidemiology and prevention of vaccine-preventable diseases. Hamborsky J, Kroger A, Wolfe S, eds. 13th ed. Washington D.C. Public Health Foundation, 2015

48. Sinovac.com [Internet]. China; Sinovac; 5/02/2021. Available in: http://www.sinovac.com/product/showproduct.php?id=66

49. Hitchings MDT, Ranzani OT, Scaramuzzini TMS, Barbosa OS, Almiron $M$, Said R. Effectiveness of CoronaVac in the setting of high SARSCoV-2 P.1 variant transmission in Brazil: a test-negative case-control 
study. MedRxiv. 01/05/2021. Available in: nhttps://www.medrxiv.org/ content/10.1101/2021.04.07.21255081v2

50. Zhang Y, Zeng G, Pan H, Li C, Hu Y, Ch K et al. Safety, tolerability, and immunogenicity of an inactivated SARS-CoV-2 vaccine in healthy adults aged 18-59 years: a randomised, double-blind, placebocontrolled, phase 1/2 clinical trial. Lancet. 2021; 21 (2): 181-192. Available in: https://www.thelancet.com/journals/laninf/article/ PIIS1473-3099(20)30843-4/fulltext\#seccestitle160

51. Centers for Disease Control and Prevention. Important information about HIV and COVID-19. 2021. Available in: https://espanol.cdc.gov/ coronavirus/2019-ncov/need-extra-precautions/hiv.html\#print

52. Xia S, Zhang Y, Wang Y, Wang H, Yang Y, Fu GG et al. Safety and immunogenicity of an inactivated SARS-CoV-2 vaccine, BBIBP-CorV: a randomised, double-blind, placebo-controlled, phase $1 / 2$ trial. Lancet. 2021. Available in: https://www.thelancet.com/pdfs/journals/ laninf/PIIS1473-3099(20)30831-8.pdf

53. medscape.com [Internet]. Emiratos Árabes Unidos: Medscape; December 09, 2020. Available in: https://www.medscape.com/ viewarticle/942310
54. Dirección de enfermedades inmunoprevenibles. Manual del Vacunador: Vacuna Sinopharm [Internet]. Argentina: Ministerio de Salud de Argentina; 2021 [Consultado 16/05/2021] Disponible en: https://bancos.salud.gob.ar/sites/default/files/2021-03/manualvacunador-sinopharm_12-3-2021.pdf

55. Bharatbiotech.com [internet]. India; Bharat Biotech; 2021 [última actualización 2021]. Disponible en: https://www.bharatbiotech.com/ covaxin.html

56. Keech C, Albert G, Cho I, Robertson A, Reed P, Neal S et al. Phase 1-2 trial of a SARS-CoV-2 recombinant spike protein nanoparticle vaccine. $N$ EnglJ Med. 2020; 383 (24): 2320-2332. doi: 10.1056/NEJMoa2026920

57. Shen X, Tang H, McDanal C, Wagh K, Fischer W, Theiler J et al. SARS-CoV-2 variant B.1.1.7 is susceptible to neutralizing antibodies elicited by ancestral spike vaccines. Cell Host Microbe. 2021; 29 (4): 529-539.e3.

58. Guebre-Xabier M, Patel N, Tian JH, Zhou B, Maciejewski S, Lam K et al. NVX-CoV2373 vaccine protects cynomolgus macaque upper and lower airways against SARS-CoV-2 challenge [Internet]. bioRxiv. 2020. Available in: http://dx.doi.org/10.1101/2020.08.18.256578 